\title{
Optimal density of radial major roads in a two-dimensional monocentric city with endogenous residential distribution and housing prices
}

\author{
Zhi-Chun Li ${ }^{\mathrm{a}, *}$, Ya-Juan Chen ${ }^{\mathrm{a}}$, Ya-Dong Wang ${ }^{\mathrm{a}}$, William H. K. Lamc, ${ }^{\mathrm{b}}$ S. C. Wong ${ }^{\mathrm{d}}$ \\ ${ }^{a}$ School of Management, Huazhong University of Science and Technology, Wuhan 430074, China \\ ${ }^{\mathrm{b}}$ Department of Civil and Structural Engineering, The Hong Kong Polytechnic University, Kowloon, \\ Hong Kong, China \\ ${ }^{\mathrm{C} S}$ Shool of Traffic \& Transportation, Beijing Jiaotong University, Beijing 100044, China \\ ${ }^{\mathrm{d}}$ Department of Civil Engineering, The University of Hong Kong, Pokfulam Road, Hong Kong, China
}

\begin{abstract}
This paper proposes an analytical urban system equilibrium model for optimizing the density of radial major roads in a two-dimensional monocentric city. The proposed model involves four types of agents: local authorities, property developers, households and household workers (i.e. commuters). The local authorities aim to maximize the total social welfare of the urban system by determining the optimal density of radial major roads in the city. The property developers seek to determine the intensity of their capital investment in the land market to maximize the net profit generated from the housing supply. The households choose residential locations that maximize their utility within a budget constraint, and the commuters choose the radial major roads that minimize their individual costs of travel between home and workplace. A heuristic solution procedure is developed to find the urban system equilibrium solution. A system optimum model is also proposed to optimize the density of radial major roads that maximizes the social welfare of the urban system. The proposed model can endogenously determine household residential distribution and land values across the city, along with the housing market structure in terms of housing prices and space. Numerical comparative static analyses of congestion pricing and road infrastructure investment (adding a new radial major road) are carried out together with evaluation of the effects of the service level of radial major roads, urban population size, and household income level on the urban economy.
\end{abstract}

Keywords: Two-dimensional monocentric city; density of radial major roads; urban system equilibrium; household residential location choice; housing market; congestion pricing.

\footnotetext{
*Corresponding author. Tel.: +86-27-8754-6073; Fax: +86-27-8755-6437.

E-mail address: smzcli@gmail.com (Z.-C. Li).
} 


\section{Introduction}

Many of the large modernized cities in China such as Beijing, Shanghai and Wuhan have dramatically increased in size in recent years as a result of China's rapid urbanization and economic growth. This rapid urban expansion has led to a more decentralized urban structure, longer average journey length, increased use of private cars, and higher level of traffic congestion, particularly within metropolitan areas. In response, local authorities have launched a number of transportation infrastructure improvement projects to increase accessibility to the city center and alleviate urban traffic congestion, including the construction of radial major roads designed to connect the city's central business district (CBD) to its suburban areas, as shown in Fig. 1. For example, the Wuhan municipal government recently approved a proposal to build a new radial major road with a total length of 15 kilometers to connect Gedian new town to Guanshan (Wuhan's CBD). Construction for this road project began in January 2012 and will be completed at the end of 2013.

The introduction of a new radial major road is expected to increase the capacity of a city's transportation system and improve the accessibility of its central area. Accordingly, the new radial major road can influence commuters' road choices, which affect the traffic flows and traffic congestion level on the major roads. However, the construction of a new major road also involves a huge capital cost. The planning and design of city's radial major roads thus involve important welfare considerations. Specifically, an oversupply of major roads can lead to wastage of resources due to an inefficient use of road space. An undersupply of roads, in contrast, can result in traffic jams generated by a lack of sufficient road capacity to accommodate travel demand. This raises an interesting question: what is the optimal density (or number) of radial major roads in terms of the total social welfare (or surplus) of an urban system, particularly when the city boundary is expanding? The answer has long-term implications for sustainable urban development, especially in rapidly expanding Chinese cities such as Beijing, Shanghai and Wuhan.

To address this important urban development issue, advanced urban spatial models must be developed to help explain and evaluate the effects of different densities of radial major roads on the urban economy. In the classical urban models that were developed by Alonso (1964), Mills (1972) and Muth (1969), the urban transportation network was assumed to be a 
perfectly divisible dense system consisting of an infinite number of radial roads. These traditional urban models cannot be used to investigate the design issue of the density (or number) of urban radial major roads and evaluate the impact of adding a new radial major road on the urban economy. One has thus to turn to a model that considers the urban structure as a sparse system of discrete radial roads. In this regard, Anas and Moses (1979) conducted a pioneering work. In their work, it was assumed that commuters either travel straight along dense surface streets to the city center or travel along circular dense surface streets to a radial road (i.e. an expressway) and then travel along the radial road to get to the city center (i.e. a circumferential-radial or ring-radial travel method). It was also assumed that the urban form was symmetric (i.e. the radial roads were evenly distributed along the circular city) and there was no traffic congestion on the radial roads. The ring-radial travel method that they proposed is useful for modeling a discrete-continuous urban system (e.g., see Baum-Snow, 2007). However, the symmetry and congestion-free assumptions may cause a significant bias in the prediction capability of the model, and thus restrict its applications in practice. For example, congestion pricing issues cannot be addressed under the congestion-free assumption.

D'Este (1987) relaxed the assumptions of a symmetric city that is free of congestion, and proposed a trip assignment model using the ring-radial travel method of Anas and Moses (1979) to model commuters' radial major road choices in a two-dimensional monocentric city with a small number of radial major roads. Wong (1994) reformulated D'Este's trip assignment model as a mathematical programming problem. These two studies assumed that the distribution of residential areas in the city was exogenously given and fixed. However, studies have shown that the improved accessibility to road travel resulting from transportation infrastructure improvements (e.g. introducing a new radial major road) can induce changes in urban land-use patterns, land values and the housing market (in terms of housing prices and space) (e.g., see McDonald and Osuji, 1995; Henneberry, 1998; O’Sullivan, 2000; Mikelbank, 2004; Ho and Wong, 2007; Li et al., 2012b). Accordingly, introduction of a new major road may change a city's household residential location choices and residential distribution, which can in turn affect the travel demand on the urban road network and thus the local authorities' decisions regarding whether to introduce new major roads into the system. Therefore, the effects that a new transportation infrastructure will have on a city's household residential location choices, land values and housing market must be considered in the planning and design of new radial major roads of urban systems. 
To account for these effects in the urban planning, this paper proposes an analytical model for investigating the design issue of the density (or number) of radial major roads in a two-dimensional monocentric city (not necessarily symmetric), as shown in Fig. 1. This paper makes two major extensions to the related literature. First, an urban system equilibrium problem is formulated to model the interactions among the following four types of agents: local authorities, property developers, households and household workers (i.e., commuters). The traffic congestion effects on the radial major roads are explicitly considered, and the household residential distribution and land values across the city along with the structure of the housing market in terms of housing prices and space can endogenously be determined. A heuristic solution procedure is also presented to solve the urban system equilibrium problem. Second, a system optimum model for optimizing the density of radial major roads is proposed to maximize the urban system's total social welfare. With use of the proposed model, numerical comparative static analyses of congestion pricing and road infrastructure investment (i.e. adding a new radial major road) are conducted. In addition, the effects of road level of service (LOS), urban population size and household income level on the urban system are also examined.

The remainder of this paper is organized as follows. The next section describes the model's basic assumptions. Section 3 formulates the equilibrium of the urban system, which includes the commuters' route choice equilibrium, the household residential location choice equilibrium and the housing demand-supply equilibrium. A heuristic solution approach is developed to solve the urban system's equilibrium problem. Section 4 proposes a system optimum model for optimizing the density of radial major roads in a two-dimensional monocentric city. Section 5 uses a numerical example to illustrate the applications of the proposed model. In particular, comparative static analyses of some policy parameters are conducted. Finally, Section 6 concludes the paper and provides recommendations for further study.

\section{Basic assumptions}

To facilitate the presentation of essential ideas without loss of generality, this paper makes the following basic assumptions. 
A1 The urban system is assumed to be a radial, closed and monocentric city, in which the total population or number of households is exogenously given and fixed and all job opportunities are located in a highly compact city center or CBD. It is further assumed that all of the land within the city boundary is owned by absentee landlords and that the value of the land at/beyond the city boundary is equal to the agricultural rent or opportunity cost of the land. These assumptions have been widely adopted in the field of urban economics (e.g., Alonso, 1964; Muth, 1969; Mills, 1972; Fujita, 1989; O’Sullivan, 2000; Kraus, 2006; McDonald, 2009).

A2 There are four types of agents in the urban economy: local authorities, property developers, households and commuters. Local authorities aim to optimize the density (or number) of radial major roads in the city to maximize the urban system's total social welfare. The property developers determine the intensity of their capital investment in the land market to maximize the net profit generated by the supply of housing. Each property developer is assumed to adopt Cobb-Douglas behavior for the housing production function (e.g., Beckmann, 1974; Quigley, 1984; Brueckner, 2007).

A3 All households are assumed to be homogeneous, implying that the income level and utility function are identical for all households. Each household has a Cobb-Douglas utility function and the household income is spent on transportation, housing and non-housing goods. The objective of each household is to maximize its own utility by choosing the optimum residential location, area of housing space and amount of other goods within the household's budget constraints (e.g., Solow, 1972, 1973; Beckmann, 1969, 1974; Anas, 1982; Fujita, 1989).

A4 Similar to Anas and Moses (1979), D’Este (1987) and Wong (1994), it is assumed that commuters traveling from their home locations to workplaces in the CBD first travel along the minor ring road that passes their particular home locations to reach a radial major road, and then proceed along the major road to reach the city center, which constitutes a ring-radial routing system (see Fig. 1). It is also assumed that each commuter chooses the ring-radial route that minimizes his/her travel cost, thereby leading to a Wardrop's user equilibrium for route choice.

A5 This paper mainly focuses on the commuters' journeys between their homes and their 
workplaces, which are compulsory (or obligatory) trips. The average number of commuters (or workers) per household is assumed to be exogenously given and fixed, and is represented as $\eta$. Every day, each worker completes one two-way commuting journey between his/her place of residence and a workplace located in the CBD. Thus, the average daily number of trips to the CBD per household is $\eta$. For example, $\eta=1$ indicates that each household makes an average of one trip to the CBD per day. The assumption that there is one commuter per household has also been adopted in previous related studies (e.g., Anas and Xu, 1999; Song and Zenou, 2006; Li et al., 2012a,b,c).

\section{Equilibrium of the urban system}

According to $\mathbf{A 2}$, there are four types of agents in the urban system: local authorities, property developers, households and commuters. The interactions among these agents lead to a number of interrelated equilibria: the commuters' ring-radial route choice equilibrium, the household residential location choice equilibrium and the housing demand-supply equilibrium. We formulate these respective equilibria in the following subsections.

\subsection{Commuters' route choice equilibrium}

\subsubsection{Travel cost}

As shown in Fig. 1, $i$ represents the ith radial major road and $M$ is the total number of radial major roads in the city. Let $x$ be the radial distance of a location from the CBD and $\theta_{i}$ the angle of a location from the nearest radial road $i$. The travel cost from location $\left(x, \theta_{i}\right)$ to the CBD via radial major road $i$ is defined as $\psi_{i}\left(x, \theta_{i}\right)$, which consists of the time and monetary costs of travel on the ring-radial routing system, i.e.,

$$
\psi_{i}\left(x, \theta_{i}\right)=\tau T_{i}\left(x, \theta_{i}\right)+C_{i}\left(x, \theta_{i}\right),
$$

where $T_{i}\left(x, \theta_{i}\right)$ and $C_{i}\left(x, \theta_{i}\right)$ are the travel time and the monetary cost from location $\left(x, \theta_{i}\right)$ to the CBD via radial major road $i$, respectively. $\tau$ is the value of travel time, which is used to convert the travel time into equivalent monetary units. 
According to $\mathbf{A 4}$, the travel time $T_{i}\left(x, \theta_{i}\right)$ consists of the time taken to travel distance $x$ from the CBD along radial major road $i$ and the time taken to travel a circular arc with a length of $x \theta_{i}$ along the minor ring road at distance $x$ from the CBD. This is represented as

$$
T_{i}\left(x, \theta_{i}\right)=T_{i}(x)+\frac{x \theta_{i}}{V_{0}}
$$

where $T_{i}(x)$ is the time required to travel distance $x$ from the CBD on radial major road $i$ and $V_{0}$ is the average vehicle travel speed on the minor ring road.

Travel time $T_{i}(x)$ depends on the level of traffic congestion on radial road $i$. Let $t_{i}\left(Q_{i}(x)\right)$ be the travel time per unit of distance around location $x$ on radial road $i$, where $Q_{i}(x)$ is the traffic volume (i.e., the number of commuters) at location $x$ on radial road i. $t_{i}\left(Q_{i}(x)\right)$ is assumed to be a strictly increasing function of traffic volume $Q_{i}(x)$ at location $x$ and can be estimated using the following Bureau of Public Roads (BPR) function

$$
t_{i}\left(Q_{i}(x)\right)=t_{i 0}\left[1.0+a_{1}\left(\frac{Q_{i}(x)}{K_{i}}\right)^{a_{2}}\right],
$$

where $t_{i 0}$ is the free-flow travel time per unit of distance on radial road $i, K_{i}$ is the capacity of radial road $i$ and $a_{1}$ and $a_{2}$ are positive parameters.

Hence, $T_{i}(x)$ can be expressed as

$$
T_{i}(x)=\int_{0}^{x} t_{i}\left(Q_{i}(w)\right) d w,
$$

where $t_{i}(\cdot)$ can be calculated using Eq. (3).

The monetary cost $C_{i}\left(x, \theta_{i}\right)$ is assumed to be a linear function of the distance traveled, as assumed in Wang et al. (2004) and Liu et al. (2009), i.e.,

$$
C_{i}\left(x, \theta_{i}\right)=c_{i 0}+c_{i 1} x+c_{i 2} x \theta_{i},
$$

where $c_{i 0}$ is the fixed cost of travel (e.g., the parking charge in the CBD per work trip) and $c_{i 1}$ and $c_{i 2}$ are the variable costs (e.g., fuel cost per unit of distance) of travel on the radial and ring roads, respectively. 
Remark 1. (Properties of the travel cost function). The first-order partial derivatives of $\psi_{i}\left(x, \theta_{i}\right)$ with regard to $x$ and $\theta_{i}$, respectively, are given by

$$
\begin{aligned}
& \frac{\partial \psi_{i}\left(x, \theta_{i}\right)}{\partial x}=\tau \frac{\partial T_{i}\left(x, \theta_{i}\right)}{\partial x}+\frac{\partial C_{i}\left(x, \theta_{i}\right)}{\partial x}=\tau\left(t_{i}\left(Q_{i}(x)\right)+\frac{\theta_{i}}{V_{0}}\right)+c_{i 1}+c_{i 2} \theta_{i}>0 \text { and } \\
& \frac{\partial \psi_{i}\left(x, \theta_{i}\right)}{\partial \theta_{i}}=\frac{\tau x}{V_{0}}+c_{i 2} x>0 .
\end{aligned}
$$

Therefore, for a given $\theta_{i}, \psi_{i}\left(x, \theta_{i}\right)$ is a strictly increasing function of the distance between $x$ and the CBD. For a given $x, \psi_{i}\left(x, \theta_{i}\right)$ is a strictly increasing function of $\theta_{i}$. This implies that the travel cost increases outwardly in the direction of the radial major road extensions and away from the radial major roads along the minor ring roads.

\subsubsection{Boundary contour}

As Fig. 1 shows, two adjacent alternative radial major roads in the two-dimensional monocentric city, $i$ and $i+1$, compete for travel demand. A watershed boundary exists that divides the area between these adjacent radial roads into two sub-areas. The watershed boundary is also called market area boundary in Anas and Moses (1979). For presentation purposes, we define $B_{i}$ as the boundary contour, which divides the travel demand between $i$ and $i+1$ into those who use $i$ and those who use $i+1$, as shown in Fig. 1. According to A4, when an equilibrium state is reached no commuter in the city has an incentive to change his/her choice of radial major road when traveling to the CBD. This means that the cost of traveling from point $B_{i}$ on the boundary contour to the CBD using radial roads $i$ and $i+1$ is identical. The travel choice equilibrium can be mathematically expressed as

$$
\psi_{i}\left(x, \hat{\theta}_{i}\right)=\psi_{i+1}\left(x, \phi_{i}-\hat{\theta}_{i}\right),
$$

where $\hat{\theta}_{i}(x)$ is the angle between major road $i$ and boundary contour $B_{i}$ at distance $x$ from the CBD and $\phi_{i}$ is the angle between radial major roads $i$ and $i+1$.

From Eqs. (1) and (8), one obtains

$$
\tau\left(T_{i}(x)+\frac{x \hat{\theta}_{i}(x)}{V_{0}}\right)+c_{i 2} x \hat{\theta}_{i}(x)=\tau\left(T_{i+1}(x)+\frac{x}{V_{0}}\left(\phi_{i}-\hat{\theta}_{i}(x)\right)\right)+c_{i 2} x\left(\phi_{i}-\hat{\theta}_{i}(x)\right) .
$$

Thus, $\hat{\theta}_{i}(x)$ can be expressed as 


$$
\hat{\theta}_{i}(x)=\frac{\phi_{i}}{2}+\frac{\tau V_{0}}{2 x\left(\tau+c_{i 2} V_{0}\right)}\left(T_{i+1}(x)-T_{i}(x)\right),
$$

where $T_{i}(x)$ can be determined by Eq. (4).

The boundary contours $B_{1}, B_{2}, \ldots, B_{M}$ can be determined by Eq. (10). The catchment area of radial major road $i$ is the sector bounded by $B_{i-1}$ and $B_{i}$.

Remark 2. (Property of angle $\hat{\theta}_{i}$ ). Suppose that the variable travel cost $c_{i 2}$ on any ring road is a constant (i.e. $c_{i 2}=c_{2}$ in Eq. (5)), we then have $\sum_{i=1}^{M} \hat{\theta}_{i}(x)=\pi$. In fact, summing both sides of Eq. (10) from $i=1$ to $M$ yields

$$
\sum_{i=1}^{M} \hat{\theta}_{i}(x)=\sum_{i=1}^{M} \frac{\phi_{i}}{2}+\frac{\tau V_{0}}{2 x\left(\tau+C_{2} V_{0}\right)}\left(T_{M+1}(x)-T_{1}(x)\right) .
$$

Note that $T_{M+1}(x)=T_{1}(x)$ holds for a circular city. Therefore, Eq. (11) can be reduced to

$$
\sum_{i=1}^{M} \hat{\theta}_{i}(x)=\sum_{i=1}^{M} \frac{\phi_{i}}{2} \text {. }
$$

Note that $\sum_{i=1}^{M} \phi_{i}=2 \pi$. Substituting it into the above equation, one immediately obtains $\sum_{i=1}^{M} \hat{\theta}_{i}(x)=\pi$.

Remark 2 reveals that the traffic flows on the radial major roads are interdependent; that is, an increase in the flow on one radial road leads to a decrease in the flow on another. It should be pointed out that the free-flow travel times and capacities (i.e., $t_{i 0}$ and $K_{i}$ in Eq. (3)) may change across the radial major roads due to the roads' varying geometries, sight distances and service levels. Thereby, $\hat{\theta}_{i}(x)=\phi_{i} / 2$ cannot hold. However, when a city is served by evenly spaced radial roads with the same free-flow travel times and capacities, as assumed in D'Este (1987), then the city’s structure is entirely symmetrical.

Remark 3. If the radial major roads in a city are evenly distributed (i.e., $\phi_{i}=\phi_{i+1}=\frac{2 \pi}{M}$, $\forall i=1,2, \ldots, M)$ and have identical travel time functions (i.e., $t_{i 0}=t_{(i+1) 0}$ and $K_{i}=K_{i+1}$, $\forall i=1,2, \ldots, M)$, then $\hat{\theta}_{i}(x)=\frac{\phi_{i}}{2}=\frac{\pi}{M}$. 


\subsubsection{Travel demand for each radial major road}

Let $q\left(x, \theta_{i}\right)$ be the hourly density of travel demand (i.e., the number of commuters per unit of land area) at location $\left(x, \theta_{i}\right), \eta$ be the average number of daily trips to the CBD per household and $\xi$ be the peak-hour factor (i.e., the ratio of peak-hour flow to the average daily flow), which is used to convert the travel demand from a daily to an hourly basis. $q\left(x, \theta_{i}\right)$ can then be defined as

$$
q\left(x, \theta_{i}\right)=\xi \eta n\left(x, \theta_{i}\right)=\lambda n\left(x, \theta_{i}\right),
$$

where $\lambda(=\xi \eta)$ is the average number of peak hour trips to the CBD per household and $n\left(x, \theta_{i}\right)$ is the household residential density at location $\left(x, \theta_{i}\right)$, which is defined later.

The hourly travel demand $Q_{i}(x)$ at location $x$ on radial major road $i$ can thus be given by

$$
Q_{i}(x)=\int_{x}^{\bar{x}_{i}} \int_{-\left(\phi_{i-1}-\hat{\theta}_{i-1}(w)\right)}^{\hat{\theta}_{i}(w)} q(w, \theta) w d \theta d w=\lambda \int_{x}^{\bar{x}_{i}} \int_{-\left(\phi_{i-1}-\hat{\theta}_{i-1}(w)\right)}^{\hat{\theta}_{i}(w)} n(w, \theta) w d \theta d w,
$$

where $\bar{X}_{i}$ is the distance from the city boundary to the CBD (or the city length) along radial road $i$ and $\hat{\theta}_{i}$ is given by Eq. (10).

The first-order derivative of $Q_{i}(x)$ with regard to $x$ is

$$
\frac{d Q_{i}(x)}{d x}=-\lambda \int_{-\left(\phi_{i-1}-\hat{\theta}_{i-1}(x)\right)}^{\hat{\theta}_{i}(x)} x n(x, \theta) d \theta .
$$

This implies that $\frac{d Q_{i}(x)}{d x}<0$. The travel demand function $Q_{i}(x)$ is therefore a decreasing function of distance $x$ from the CBD.

Remark 4. In view of the above, once the household residential density $n\left(x, \theta_{i}\right)$ is known, one can then determine the travel demand $Q_{i}(x)$ by Eq. (14) or (15), the travel time $T_{i}(x)$ by Eq. (4), the travel cost $\psi_{i}\left(x, \theta_{i}\right)$ by Eq. (1) and the boundary contour set $\left\{B_{i}, i=1,2, \ldots, M\right\}$ or, equivalently, the critical angle set $\left\{\hat{\theta}_{i}(x), i=1,2, \ldots, M\right\}$ in terms of Eq. (10). 


\subsection{Housing market equilibrium}

\subsubsection{Household residential location choice behavior}

To model household residential location choice behavior, we first define the household utility function. In this paper, the following Cobb-Douglas form of the household utility function is adopted

$$
U\left(x, \theta_{i}\right)=z\left(x, \theta_{i}\right)^{\alpha} g\left(x, \theta_{i}\right)^{\beta}, \alpha, \beta>0, \alpha+\beta=1,
$$

where $U\left(x, \theta_{i}\right)$ is the utility function of households at location $\left(x, \theta_{i}\right), \alpha$ and $\beta$ are positive constants, $z\left(x, \theta_{i}\right)$ is the composite non-housing goods consumed per household at location $\left(x, \theta_{i}\right)$, for which the price is normalized to 1 , and $g\left(x, \theta_{i}\right)$ is the average consumption of housing per household at location $\left(x, \theta_{i}\right)$, which is measured in square meters of floor space.

According to $\mathbf{A 3}$, it is assumed that each household chooses the residential location that maximizes its own utility, subject to budget constraints. The household utility maximization problem can be represented as

$$
\begin{array}{ll} 
& \max _{z, g} U\left(x, \theta_{i}\right)=z\left(x, \theta_{i}\right)^{\alpha} g\left(x, \theta_{i}\right)^{\beta}, \\
\text { s.t. } & z\left(x, \theta_{i}\right)+p\left(x, \theta_{i}\right) g\left(x, \theta_{i}\right)=Y-E\left(x, \theta_{i}\right),
\end{array}
$$

where $p\left(x, \theta_{i}\right)$ is the average annual rental price per unit of housing floor area at location $\left(x, \theta_{i}\right), Y$ is the average annual household income and $E\left(x, \theta_{i}\right)$ is the average annual travel cost (or expenditure) from location $\left(x, \theta_{i}\right)$ to the CBD along the ring-radial routing system, which can be measured by

$$
E\left(x, \theta_{i}\right)=2 \rho \cdot \psi_{i}\left(x, \theta_{i}\right),
$$

where the " 2 " denotes a round-trip journey between location $\left(x, \theta_{i}\right)$ and the CBD and $\rho$ is the average annual number of trips to the CBD per household. The (one-way) average travel cost, $\psi_{i}\left(x, \theta_{i}\right)$, from location $\left(x, \theta_{i}\right)$ to the CBD can be determined by Eq. (1).

Substituting $z\left(x, \theta_{i}\right)$ in Eq. (18) into Eq. (17) and setting the derivative of $U(\cdot)$ with regard to $g$ equal to zero (i.e., $d U / d g=0$ ), one obtains 


$$
g\left(x, \theta_{i}\right)=\frac{\beta\left(Y-E\left(x, \theta_{i}\right)\right)}{p\left(x, \theta_{i}\right)} .
$$

When the household residential location choice equilibrium state is reached, all households in the city have the same utility level regardless of their residential locations. Let $u$ be the common utility level. The following equation then holds

$$
u=z\left(x, \theta_{i}\right)^{\alpha} g\left(x, \theta_{i}\right)^{\beta}=\left(Y-E\left(x, \theta_{i}\right)-p\left(x, \theta_{i}\right) g\left(x, \theta_{i}\right)\right)^{\alpha} g\left(x, \theta_{i}\right)^{\beta},
$$

where $g(\cdot)$ and $p(\cdot)$ can be derived from Eqs. (20) and (21) as functions of the common utility level $u$, as follows:

$$
\begin{aligned}
& g\left(x, \theta_{i}, u\right)=\alpha^{-\alpha / \beta}\left(Y-E\left(x, \theta_{i}\right)\right)^{-\alpha / \beta} u^{1 / \beta} \text { and } \\
& p\left(x, \theta_{i}, u\right)=\alpha^{\alpha / \beta} \beta\left(Y-E\left(x, \theta_{i}\right)\right)^{1 / \beta} u^{-1 / \beta} .
\end{aligned}
$$

Eqs. (22) and (23) describe the equilibrium amount of housing floor space per household and the equilibrium price per unit of housing floor space, respectively, at location $\left(x, \theta_{i}\right)$. These equations show that for a given level of utility, the average housing price decreases and the average housing floor space per household increases as the travel cost increases, and vice versa.

\subsubsection{Property developers' housing production behavior}

This subsection focuses on the supply side of the housing market. In this paper, property developers are assumed to behave in keeping with the following Cobb-Douglas form of the housing production function

$$
h\left(S\left(x, \theta_{i}\right)\right)=\mu \cdot\left(S\left(x, \theta_{i}\right)\right)^{b}, 0<b<1,
$$

where $h\left(S\left(x, \theta_{i}\right)\right)$ is the housing supply per unit of land area at location $\left(x, \theta_{i}\right), S\left(x, \theta_{i}\right)$ is the capital investment per unit of land area at location $\left(x, \theta_{i}\right)$ (also referred to as capital investment intensity) and $\mu$ and $b$ are positive parameters.

Let $r\left(x, \theta_{i}\right)$ be the rent or value per unit of land area at location $\left(x, \theta_{i}\right)$ and $k$ be the price of capital (i.e., the interest rate). The net profit per unit of land area, $\Lambda\left(x, \theta_{i}\right)$, at location $\left(x, \theta_{i}\right)$ can then be given by 


$$
\Lambda\left(x, \theta_{i}\right)=p\left(x, \theta_{i}\right) h\left(S\left(x, \theta_{i}\right)\right)-\left(r\left(x, \theta_{i}\right)+k S\left(x, \theta_{i}\right)\right),
$$

where the price per unit of housing floor space $p(\cdot)$ is given by Eq. (23). The first term on the right-hand side of Eq. (25) is the total revenue from housing leases. The final two terms are the land rent cost and the capital cost, respectively.

From A2, each property developer in the housing market aims to maximize his/her own net profit by determining the optimal capital investment intensity, which is expressed as

$$
\max _{S} \Lambda\left(x, \theta_{i}\right)=p\left(x, \theta_{i}\right) \mu S^{b}-\left(r\left(x, \theta_{i}\right)+k S\right) .
$$

The first-order optimality condition of the maximization problem (26) yields

$$
\frac{\partial \Lambda}{\partial S}=p\left(x, \theta_{i}\right) \mu b S^{b-1}-k=0 .
$$

Substituting $p(\cdot)$ in Eq. (23) into Eq. (27) produces the capital investment intensity as a function of the utility level $u$, i.e.,

$$
S\left(x, \theta_{i}, u\right)=\left(\alpha^{\alpha / \beta} \beta\left(Y-E\left(x, \theta_{i}\right)\right)^{1 / \beta} u^{-1 / \beta} \mu b k^{-1}\right)^{\frac{1}{1-b}} .
$$

The household residential density $n\left(x, \theta_{i}\right)$ at location $\left(x, \theta_{i}\right)$ can thus be calculated by

$$
n\left(x, \theta_{i}\right)=\frac{h\left(S\left(x, \theta_{i}, u\right)\right)}{g\left(x, \theta_{i}, u\right)}=\left(\mu \alpha^{\alpha / \beta}\left(\beta b k^{-1}\right)^{b}\right)^{1 /(1-b)} u^{1 /(\beta b-\beta)}\left(Y-E\left(x, \theta_{i}\right)\right)^{(\alpha+\beta b) /(\beta-\beta b)} .
$$

Note that under perfect competition, the property developers earn zero profit, thus

$$
r\left(x, \theta_{i}\right)=\mu p\left(x, \theta_{i}\right)\left(S\left(x, \theta_{i}\right)\right)^{b}-k S\left(x, \theta_{i}\right) .
$$

Substituting Eqs. (23) and (28) into Eq. (30) yields

$$
r\left(x, \theta_{i}, u\right)=k\left(\frac{1}{b}-1\right)\left(\alpha^{\alpha / \beta} \beta\left(Y-E\left(x, \theta_{i}\right)\right)^{1 / \beta} u^{-1 / \beta} \mu b k^{-1}\right)^{\frac{1}{1-b}} .
$$

Eqs. (28), (29) and (31) define the equilibrium capital investment intensity, residential density and land value at any location within the city, respectively. It can be seen that given the utility level $u$, the capital investment intensity, residential density and land value all decrease as either the travel cost or the interest rate increases, and vice versa. 


\subsubsection{Housing demand-supply equilibrium}

Balancing the housing supply and demand requires that all households fit exactly inside the city boundary, i.e.,

$$
\sum_{i=1}^{M} \int_{-\left(\phi_{i-1}-\hat{\theta}_{i-1}\right)}^{\hat{\theta}_{i}} \int_{0}^{\bar{x}_{i}(\theta)} n(x, \theta) x d x d \theta=N
$$

where $N$ is the total number of households in the city. The left-hand side of Eq. (32) is the sum of the number of households in the catchment areas for all of the radial major roads within a city.

The equilibrium rent per unit of land area devoted to housing at the city fringe $\left(\bar{x}_{i}, \theta\right)$ equals the exogenous agricultural rent or the opportunity cost of the land; that is,

$$
r\left(\bar{x}_{i}(\theta), \theta, u\right)=r_{a},
$$

where $r_{a}$ is a constant agricultural rent.

Using Eq. (31), Eq. (33) can be rewritten as

$$
k\left(\frac{1}{b}-1\right)\left(\alpha^{\alpha / \beta} \beta\left(Y-E\left(\bar{x}_{i}, \theta\right)\right)^{1 / \beta} u^{-1 / \beta} \mu b k^{-1}\right)^{\frac{1}{1-b}}=r_{a} .
$$

Remark 5. Eqs. (32) and (34), together with Eqs. (22), (23), (28), (29) and (31), determine the housing market equilibrium. Given the travel cost $E\left(x, \theta_{i}\right)$ or $\psi_{i}\left(x, \theta_{i}\right)$ (see Eq. (19)), one can determine the values of household utility level $u$ and the city boundary $\bar{x}_{i}$ by solving the system of Eqs. (32) and (34) and thus the following functions: $g\left(x, \theta_{i}\right), p\left(x, \theta_{i}\right)$, $S\left(x, \theta_{i}\right), n\left(x, \theta_{i}\right)$ and $r\left(x, \theta_{i}\right)$.

\subsection{Calculating the equilibrium solution for the urban system}

In this subsection, a procedure for calculating the equilibrium solution of the urban system is presented. Given the household residential density $n\left(x, \theta_{i}\right)$, the commuters' route choice equilibrium problem can determine the functions $Q_{i}(x), T_{i}(x)$ and $\psi_{i}\left(x, \theta_{i}\right)$ in addition to

the boundary contours $\left\{B_{i}, i=1,2, \ldots, M\right\}$. In contrast, given the travel cost $\psi_{i}\left(x, \theta_{i}\right)$, the 
housing market equilibrium problem can determine the functions $n\left(x, \theta_{i}\right), g\left(x, \theta_{i}\right)$, $p\left(x, \theta_{i}\right), S\left(x, \theta_{i}\right)$ and $r\left(x, \theta_{i}\right)$ and the constants $u$ and $\bar{x}_{i}$. The interdependence of the interrelated equilibria leads to a stationary solution with regard to residential density and travel costs, as follows:

$$
\mathbf{n}^{(0)} \rightarrow \boldsymbol{\psi}^{(0)} \rightarrow \mathbf{n}^{(1)} \rightarrow \boldsymbol{\psi}^{(1)} \rightarrow \cdots \rightarrow\left(\mathbf{n}^{*}, \boldsymbol{\psi}^{*}\right),
$$

where the bolded symbols represent the vectors of the corresponding variables; that is, $\boldsymbol{\psi}=\left\{\psi_{i}\left(x, \theta_{i}\right)\right\}$ and $\mathbf{n}=\left\{n\left(x, \theta_{i}\right)\right\}$.

The step-by-step procedure for determining the (stationary) equilibrium solution of the urban system is as follows.

Step 1. Choose initial values for the household residential density $\mathbf{n}^{(0)}$, then determine the travel demand vector $\mathbf{Q}^{(0)}=\left\{Q_{i}^{(0)}(x)\right\}$ in terms of Eqs. (13) and (14), the travel time vector $\mathbf{T}^{(0)}=\left\{T_{i}^{(0)}(x)\right\}$ by Eq. (4), the travel cost vector $\boldsymbol{\psi}^{(0)}$ by Eq. (1) and the critical angle vector $\hat{\boldsymbol{\theta}}^{(0)}=\left\{\hat{\theta}_{i}^{(0)}(x)\right\}$ according to Eq. (10). Set the iteration counter to $l=1$.

Step 2. Solving the system of Eqs. (32) and (34) yields the values of $u^{(l)}$ and $\left\{\bar{x}_{i}^{(l)}\right\}$. The values of the vectors $\mathbf{g}^{(l)}, \mathbf{p}^{(l)}, \mathbf{S}^{(l)}, \mathbf{n}^{(l)}$ and $\mathbf{r}^{(l)}$ can then be obtained by substituting $u^{(l)}$ and $\left\{\bar{X}_{i}^{(l)}\right\}$ into Eqs. (22), (23), (28), (29) and (31).

Step 3. Determine the travel demand vector $\mathbf{Q}^{(l)}$ in terms of Eqs. (13) and (14) and the travel time vector $\mathbf{T}^{(l)}$ according to Eq. (4). The auxiliary travel cost vector $\tilde{\boldsymbol{\Psi}}^{(l)}$ can then be obtained by Eq. (1) and thus, the critical angle vector $\hat{\boldsymbol{\theta}}^{(l)}$ by Eq. (10).

Step 4. Update the travel cost according to $\boldsymbol{\psi}^{(l+1)}=\boldsymbol{\psi}^{(l)}+\left(\tilde{\boldsymbol{\psi}}^{(l)}-\boldsymbol{\psi}^{(l)}\right) / l$.

Step 5. If the relative gap $\left\|\boldsymbol{\psi}^{(l+1)}-\boldsymbol{\psi}^{(l)}\right\| /\left\|\boldsymbol{\psi}^{(l)}\right\|$ is smaller than a pre-specified tolerance, then stop. Otherwise, set $l=l+1$ and go to Step 2 .

In Step 1, the initial household residential density can be assumed to be uniform across this city. In Step 2, the system of Eqs. (32) and (34) can be solved using an iterative method in which the decision variables $\left\{\bar{X}_{i}\right\}$ and $u$ are sequentially updated while holding the value of 
the other variable fixed. Specifically, one chooses initial values for $\left\{\bar{x}_{i}\right\}$, then solves Eq. (32) to obtain the value of $u$. The values of $\left\{\bar{x}_{i}\right\}$ can then be updated by solving Eq. (34) using the bi-section method for the value of $u$ that has just been obtained. Repeating the iterative process yields the solutions for $\left\{\bar{x}_{i}\right\}$ and $u$.

\section{Model for optimizing the density of radial major roads}

As previously stated, local authorities aim to maximize the total social welfare (SW) of the urban system by optimizing the density of the radial major roads within the two-dimensional monocentric city. The social welfare, which takes into account the benefits of all parties in the urban system, is defined as the total utility of all households plus the aggregate rent received by the absentee landlords minus the total road investment cost. The social welfare maximization problem can be formulated as

$$
\max _{M} \mathrm{SW}=\zeta u N+\sum_{i=1}^{M} \int_{-\left(\phi_{i-1}-\hat{\theta}_{i-1}\right)}^{\hat{\theta}_{i}} \int_{0}^{\bar{x}_{i}(\theta)}\left(r(x, \theta)-r_{a}\right) x d \theta d x-\sum_{i=1}^{M} \Phi_{i},
$$

where $\zeta$ is a parameter that converts the utility level of households into the equivalent monetary units. $r(x, \theta)$ can be determined using the equilibrium formulation of the urban system proposed in the previous section. $\Phi_{i}$ represents the construction cost of radial major road $i$. The first term on the right-hand side of Eq. (36) denotes the total utility of all households, the second term denotes the aggregate rent received by the absentee landlords, and the third term denotes the total construction cost of all radial major roads.

It is assumed that the construction cost, $\Phi_{i}$, of radial major road $i$ is a function with respect to the length, $\bar{x}_{i}$, of radial road $i$ and its capacity $K_{i}$, as follows:

$$
\Phi_{i}=\delta \bar{x}_{i} K_{i}
$$

where $\delta$ is a positive constant. Eq. (37) indicates that the road construction cost is proportional to the road length and width.

Note that the model (36) is an integer programming problem with the number of radial major roads as the decision variable. In general, this type of problem is difficult to solve (Li et al., 2011, 2012c). Fortunately, the number of radial major roads in a city is finite. Therefore, a 
simple approach to determine the optimal density of radial major roads is to compare the resultant values of objective function (36) using different numbers of radial major roads.

\section{Model applications}

In this section, a numerical example is given to illustrate the applications of the proposed model and the contributions of this paper. The numerical example is intended to ascertain the effects of road level of service (LOS), urban population size (number of households) and household income level on the optimal density of the radial major roads and the performance of the urban system. It is also used to investigate the effects of various urban policies, such as congestion pricing and road infrastructure investment (introducing a new radial major road) on the urban economy.

In order to quantitatively evaluate the effects of congestion pricing scheme and adding a new radial major road, some performance measures are defined as follows:

$$
\begin{aligned}
& \text { City area (or size) }=\sum_{i=1}^{M} \int_{-\left(\phi_{i-1}-\hat{\theta}_{i-1}\right)}^{\hat{\theta}_{i}} \int_{0}^{\bar{x}_{i}(\theta)} x d x d \theta, \\
& \text { Average household residential density }=N / \text { city area, } \\
& \text { Average housing space per family }=\sum_{i=1}^{M} \int_{-\left(\phi_{i-1}-\hat{\theta}_{i-1}\right)}^{\hat{\theta}_{i}} \int_{0}^{\bar{x}_{i}(\theta)} g(x, \theta) n(x, \theta) x d x d \theta / N, \\
& \text { Average housing price }=\sum_{i=1}^{M} \int_{-\left(\phi_{i-1}-\hat{\theta}_{i-1}\right)}^{\hat{\theta}_{i}} \int_{0}^{\bar{x}_{i}(\theta)} p(x, \theta) x d x d \theta / \text { city area , } \\
& \text { Average land value }=\sum_{i=1}^{M} \int_{-\left(\phi_{i-1}-\hat{\theta}_{i-1}\right)}^{\hat{\theta}_{i}} \int_{0}^{\bar{x}_{i}(\theta)} r(x, \theta) x d x d \theta / \text { city area , } \\
& \text { Average capital investment intensity }=\sum_{i=1}^{M} \int_{-\left(\phi_{i-1}-\hat{\theta}_{i-1}\right)}^{\hat{\theta}_{i}} \int_{0}^{\bar{x}_{i}(\theta)} S(x, \theta) x d x d \theta / \text { city area . }
\end{aligned}
$$

For presentation purposes, in the numerical experiment, all of the radial major roads in the city are assumed to have identical free-flow travel times and capacities. The baseline values (i.e. base case) for the model's input parameters are shown in Table 1. In the following analysis, unless specifically stated otherwise, the input data are identical to those of the base case. The computer code for the numerical experiment (written in programming language $\mathrm{C}$ ) is not shown in the paper so as to save space, but available from the authors on request.

5.1. Effects of road LOS, urban population size, and household income level on density of 
radial major roads

We first investigate the effects of the road LOS, number of households (or population size), and household income level on the optimal density of the radial major roads. Fig. 2 plots the contour of the annual total social welfare of the urban system in the space of the road LOS (i.e. road capacity) and the number (or density) of radial major roads. It can be seen that for a given road capacity, as the density of the major roads increases, the annual total social welfare of the urban system first increases and then decreases. The maximum social welfare for a given road capacity (or LOS) occurs at the point of tangency between the horizontal line passing through the given road capacity and the social welfare contour. For example, the horizontal line with the road capacity of 4950 vehicles per hour touches a social welfare contour at point F, as shown in Fig. 2. This means that when the road capacity is 4950 vehicles per hour, the optimal number of the radial major roads is 7. Any point on the dotted curve in Fig. 2 represents the maximum social welfare for a given road LOS. It can also be seen that as the road capacity (or LOS) increases, the optimal number of the radial major roads decreases, and vice versa.

Fig. 3 displays the change of the annual total social welfare of the urban system with the total number of households and the number (or density) of the radial major roads. It can be seen that for a given number of households, the associated horizontal line touches a social welfare contour, implying that there is an optimal number of the radial roads. For instance, when the number of households is 300,000 , the optimal number of the radial roads is 8 . The dotted curve in Fig. 3 defines the maximum social welfare levels for different numbers of households. It shows that as the number of households (or population size) grows, the optimal number of the radial roads increases.

Fig. 4 indicates the change of the annual total social welfare of the urban system with the household income level and the number of radial major roads. It can be observed that the optimal number of the radial major roads would be 7 regardless of the household income level. This implies that the household income level has no apparent effect on the optimal density of the radial major roads.

\subsection{Effects of optimal congestion pricing on density of radial major roads}


In the literature, congestion pricing schemes generally include first-best scheme, cordon-based scheme, and distance-based scheme (see Mitchell et al., 2005; Li et al., 2012a). The first-best and cordon-based schemes have been widely explored in the field of urban economics (for more details, see Mun et al., 2003; Verhoef, 2005; Anas and Rhee, 2006; Li et al., 2012a; De Lara et al., 2013). Here, we investigate the effects of the distance-based congestion pricing scheme on the optimal density of the radial major roads. The distance-based pricing scheme implies that the toll is proportional to the distance traveled, that is, the product of the travel distance and the toll per unit of distance. Fig. 5 depicts the contour of the annual total social welfare of the urban system in the toll-road density space. It can be seen that the maximum social welfare occurs at the toll level of $\$ 0.36$ per kilometer and 6 major roads, causing a social welfare of $\$ 10.389$ billion per year (see Table 2).

Table 2 summarizes the effects of the congestion pricing scheme on the urban system. It can be seen that implementation of the congestion pricing scheme causes a decrease in the city size (or city area) by 234 square kilometers (from 1261.1 to 1027.0 square kilometers). This is because the additional tolls under the distance-based congestion pricing scheme increase the annual transportation expenditures of households and thus lead them to move towards the city center. As a result, the average residential density, average housing price, average capital investment intensity, and average land value increase by 90 households per square kilometer, \$92.3 per square meter, \$25.4 million per square kilometer, and \$0.6 million per square kilometer, respectively. However, the average housing space per household decreases by 0.6 square meter. In addition, it can also be seen that the congestion pricing scheme leads to a decrease in the household utility level by 4.6 utility units due to an increased travel cost, and in road construction cost by $\$ 55.8$ million due to a reduced city size, but the aggregate land rent increases by $\$ 62.8$ million due to an increased land value. As a result, the annual social welfare of the urban system increases by $\$ 18.8$ million (from $\$ 10370.2$ to $\$ 10389.0$ million).

\subsection{Effects of a new additional radial major road on urban system}

In this subsection, we address the following two problems: (1) where is optimal location of a new additional radial major road? (2) What are the effects of a new additional radial major road on the urban system? For illustration purposes, we consider a city with five existing radial major roads, which are numbered as $1,2,3,4$, and 5, respectively, as shown in bolded lines in Fig. 6. The angles among the five radial major roads are $120^{\circ}, 40^{\circ}, 50^{\circ}, 60^{\circ}$, and $90^{\circ}$, 
respectively.

\subsubsection{Optimal location of a new additional radial road}

In order to determine the optimal location of a new additional radial major road in the city shown in Fig. 6, Fig. 7 depicts the annual social welfare curves when the new additional radial road is located between any two existing radial roads, respectively. In Fig. $7, R_{i j}$ represents to insert the new additional radial road in between roads $i$ and $j$. It can be seen in this figure that the optimal location of the new additional radial road should be located between radial roads 1 and 2 with 0.92 radian (i.e. 52.7) from the radial road 1 (shown in dotted line in Fig. 6), which results in the maximum social welfare level of $\$ 10.359$ billion per year.

\subsubsection{Comparison of urban system performances before and after adding a new radial road}

Finally, we examine the effects of an additional radial road (shown in Fig. 6) on the urban system. Figs. 8a-d and 8a'-d' plot the contours of the household residential density, housing price, housing space per household, and capital investment intensity across the city before and after introducing a new radial road, respectively. It can be seen that introduction of a new radial road leads to a change in the urban shape from a pentagram (i.e. a five-pointed star) to a hexagram (i.e. a six-pointed star). In the meantime, it also leads to a decrease in the household residential density, the housing price, and the capital investment intensity, but an increase in the housing space per household. Specifically, the household residential densities on the city boundary and in the city center decrease by 0.5 (from 61 to 60.5) and 648 (from 3992 to 3344) households per square kilometer respectively, as shown in Figs. 8a and a'. The housing prices on the city boundary and in the city center (shown in Figs. 8b and b') decrease by $\$ 3$ (from $\$ 1248$ to \$1245) and \$250 (from \$4836 to \$4586) per square meter, respectively. The housing spaces per household on the city boundary and in the city center (see Figs. 8c and c') increase by 0.18 (from 13.24 to 13.42 ) and 0.26 (from 4.79 to 5.05 ) square meter, respectively. The capital investment intensities on the city boundary and in the city center decrease by $\$ 0.1$ (from \$14.2 to \$14.1) and \$211 (from \$1295 to \$1084) million per square kilometer respectively, as shown in Figs. 8d and d'. 
Table 3 further summarizes the effects of adding a new radial road on the performance of the urban system. It shows that introduction of a new radial road increases the size of the city by 87.8 square kilometers and the average housing space per household by 0.2 square meter. However, it also decreases the average household residential density from 432.9 to 402.3 households per square kilometer, the average housing price from \$2094.8 to \$2067.7 per square kilometer, the average land value from \$2.6 to \$2.5 million per square kilometer, and the average capital investment intensity from $\$ 122.7$ to $\$ 114.7$ million per square kilometer, respectively. As a result, the household utility level increases 2.7 utility units, the total land rent decreases by $\$ 8.3$ million, the road construction cost increases by $\$ 70$ million, and the annual social welfare increases by $\$ 29$ million.

\section{Conclusion and further studies}

This paper investigated the design problem of the density of radial major roads in a two-dimensional monocentric city. The urban system concerned included four types of agents: local authorities, property developers, households and commuters. The interdependence among these agents induces a number of interrelated equilibria; namely, the housing demand-supply equilibrium, household residential location choice equilibrium and commuters' ring-radial route choice equilibrium. Based on the urban system equilibrium analysis, a heuristic solution approach was developed to solve the urban system's equilibrium problem and a system optimum model was proposed to determine the optimal density of the radial major roads so as to maximize the urban system's social welfare. In the proposed model, the household residential distribution, capital investment intensity, land values, housing prices and housing space can all be endogenously determined. An illustrative numerical example was given to assess the effects of road level of service (LOS), urban population size and household income level on the optimal density of the radial major roads. The comparative static analyses of the congestion pricing and road infrastructure investment were also carried out. The proposed model can be served as a useful tool for the long-term strategic planning of sustainable urban developments and for evaluation of various transportation, land-use and housing policies.

The proposed model offers some new insights and interesting findings. First, the road capacity (or LOS) and the number of households (or population size) have a significant effect 
on the optimal density (or number) of the radial major roads. Specifically, the optimal number of the radial major roads increases with the increase of the number of households but decreases with the increase of the road LOS. However, the household income level may have little impact on the optimal density of the radial roads. Second, congestion pricing scheme can decrease the size of city and thus lead to a more compact city. It can also increase the social welfare of the urban system and save the government's investment on road infrastructure projects at the expense of the household utility. Third, the introduction of an additional radial major road can increase the size of city and thus cause a more decentralized city. Households and the whole urban system can benefit from the road infrastructure investment that is funded by the government.

Although the modeling methodology proposed in this paper provides a new avenue for modeling the interactions among land use, housing market and transportation infrastructure improvements, further extensions are necessary. First, the city of interest was assumed to be monocentric in this paper. However, modern cities generally have multiple business and commercial centers. Therefore, further studies could improve the model by shifting from a monocentric city to a polycentric structure (Wong, 1998; Kloosterman and Musterd, 2001; Yin et al., 2013; Ho et al., 2013). Second, this paper focused mainly on the auto mode, thus ignoring the competition and substitution effects between auto and transit modes. To incorporate the interaction and competition between different transportation modes, the single-mode system should be extended into a multi-modal system (Capozza, 1976; Anas and Moses, 1979; Li et al., 2012a). Third, all of the households in this paper were assumed to be homogenous. However, an empirical study by Kwon (2003) showed that household income level may affect residential location choice. Therefore, future models should be extended to consider the choice behavior of households with different income levels and demographic characteristics.

\section{Acknowledgments}

The authors would like to thank the editor, Professor Yves Zenou, and two anonymous referees for their helpful comments and suggestions on an earlier draft of the paper. The work described in this paper was jointly supported by grants from the National Natural Science Foundation of China $(71222107,71171013)$, the Research Foundation for the Authors of 
National Excellent Doctoral Dissertations (China) (200963), the Doctoral Fund of Ministry of Education of China (20120142110044), and the Fok Ying Tung Education Foundation (132015).

\section{References}

Alonso, W., 1964. Location and land use: toward a general theory of land rent. Massachusetts: Harvard University Press, Cambridge.

Anas, A., 1982. Residential location markets and urban transportation. New York: Academic Press.

Anas, A., Moses, L.N., 1979. Mode choice, transport structure and urban land use. Journal of Urban Economics, 6 (2), 228-246.

Anas, A., Rhee, H.J., 2006. Curbing excess sprawl with congestion tolls and urban boundaries. Regional Science and Urban Economics, 36 (4), 510-541.

Anas, A., Xu, R., 1999. Congestion, land use, and job dispersion: a general equilibrium model. Journal of Urban Economics, 45 (3), 451-473.

Baum-Snow, N., 2007. Suburbanization and transportation in the monocentric model. Journal of Urban Economics, 62 (3), 405-423.

Beckmann, M.J., 1969. On the distribution of urban rent and residential density. Journal of Economic Theory, 1 (1), 60-67.

Beckmann, M.J., 1974. Spatial equilibrium in housing market. Journal of Urban Economics, 1 (1), 99-107.

Brueckner, J.K., 2007. Urban growth boundaries: an effective second-best remedy for unpriced traffic congestion? Journal of Housing Economics, 16 (3-4), 263-273.

Capozza, D.R., 1976. Land use in a city with two modes of transportation. Southern Economic Journal, 42 (3), 442-450.

De Lara, M., de Palma, A., Kilani, M., Piperno, S., 2013. Congestion pricing and long term urban form: Application to Paris region. Regional Science and Urban Economics, 43 (2), 282-295.

D’Este, G., 1987. Trip assignment to radial major roads. Transportation Research Part B, 21 (6), 433-442.

Fujita, M., 1989. Urban economic theory. Cambridge: Cambridge University Press.

Henneberry, J., 1998. Transport investment and house prices. Journal of Property Valuation 
and Investment, 16 (2), 144-158.

Ho, H.W., Wong, S.C., 2007. Housing allocation problem in a continuum transportation system. Transportmetrica, 3 (1), 21-39.

Ho H.W., Wong S.C., Sumalee, A., 2013. A congestion-pricing problem with a polycentric region and multi-class users: a continuum modeling approach. Transportmetrica, in press. DOI:10.1080/18128602.2011.621652.

Kloosterman, R.C., Musterd, S., 2001. The polycentric urban region: towards a research agenda. Urban Studies, 38 (4), 623-633.

Kraus, M., 2006. Monocentric cities. In Arnott, R. J., McMillan, D. P. (Eds.), A Companion to urban economics (pp. 96-108). Oxford: Blackwell Publishing.

Kwon, Y., 2003. The effect of a change in wages on welfare in a two-class monocentric city. Journal of Regional Science, 43 (1), 63-72.

Li, Z.C., Lam, W.H.K., Wong, S.C., 2011. On the allocation of new lines in a competitive transit network with uncertain demand and scale economies. Journal of Advanced Transportation, 45 (4), 233-251.

Li, Z.C., Lam, W.H.K., Wong, S.C., 2012a. Modeling intermodal equilibrium for bimodal transportation system design problems in a linear monocentric city. Transportation Research Part B, 46 (1), 30-49.

Li, Z.C., Lam, W.H.K., Wong, S.C., Choi, K., 2012b. Modeling the effects of integrated rail and property development on the design of rail line services in a linear monocentric city. Transportation Research Part B, 46 (6), 710-728.

Li, Z.C., Lam, W.H.K., Wong, S.C., Sumalee, A., 2012c. Design of a rail transit line for profit maximization in a linear transportation corridor. Transportation Research Part E, 48 (1), 50-70.

Liu, T.L., Huang, H.J., Yang, H., Zhang, X., 2009. Continuum modeling of park-and-ride services in a linear monocentric city with deterministic mode choice. Transportation Research Part B, 43 (6), 692-707.

McDonald, J.F., 2009. Calibration of a monocentric city model with mixed land use and congestion. Regional Science and Urban Economics, 39 (1), 90-96.

McDonald, J.F., Osuji, C.I., 1995. The effect of anticipated transportation improvement on residential land values. Regional Science and Urban Economics, 25 (3), 261-278.

Mikelbank, B.A., 2004. Spatial analysis of the relationship between housing values and investments in transportation infrastructure. Annals of Regional Science, 38 (4), 705-726.

Mills, E.S., 1972. Urban economics. Illinois: Scott Foresman, Glenview. 
Mitchell, G., Namdeo, A., Milne, D., 2005. The air quality impact of cordon and distance based road user charging: an empirical study of Leeds, UK. Atmospheric Environment, 39 (33), 6231-6242.

Muth, R.F., 1969. Cities and housing. Chicago: University of Chicago Press.

Mun, S.I., Konishi, K.J., Yoshikawa, K., 2003. Optimal cordon pricing. Journal of Urban Economics, 54 (1), 21-38.

O’Sullivan, A., 2000. Urban economics. Boston: Irwin/McGraw-Hill.

Quigley, J.M., 1984. The production of housing services and the derived demand for residential energy. RAND Journal of Economics, 15 (4), 555-567.

Solow, R.M., 1972. Congestion, density and the use of land in transportation. Swedish Journal of Economics, 74 (1), 161-173.

Solow, R.M., 1973. Congestion cost and the use of land for streets. Bell Journal of Economics and Management Science, 4 (2), 602-618.

Song, Y., Zenou, Y., 2006. Property tax and urban sprawl: theory and implications for US cities. Journal of Urban Economics, 60 (3), 519-534.

Verhoef, E.T., 2005. Second-best congestion pricing schemes in the monocentric city. Journal of Urban Economics, 58 (3), 367-388.

Wang, J.Y.T., Yang, H., Lindsey, R., 2004. Locating and pricing park-and-ride facilities in a linear monocentric city with deterministic mode choice. Transportation Research Part B, 38 (8), 709-731.

Wong, S.C., 1994. An alternative formulation of D’Este's trip assignment model. Transportation Research Part B, 28 (3), 187-196.

Wong, S.C., 1998. Multi-commodity traffic assignment by continuum approximation of network flow with variable demand. Transportation Research Part B, 32 (8), 567-581.

Yin, J., Wong, S.C., Sze, N.N., Ho, H.W., 2013. A continuum model for housing allocation and transportation emission problems in a polycentric city. International Journal of Sustainable Transportation, 7 (4), 275-298. 


\section{List of Figures and Tables}

Fig. 1. A typical circular city with radial major roads.

Fig. 2. Change of annual social welfare (billion \$) with the number of radial major roads and the road capacity.

Fig. 3. Change of annual social welfare (billion \$) with the number of radial major roads and the total number of households.

Fig. 4. Change of annual social welfare (billion \$) with the number of radial major roads and the household income level.

Fig. 5. Change of annual social welfare (billion \$) with the number of radial major roads and the toll per unit of distance.

Fig. 6. A city with five radial major roads.

Fig. 7. Change of annual social welfare with the location of a new additional major road.

Fig. 8. (a)-(d) represent household residential density (households $\left./ \mathrm{km}^{2}\right)$, housing price $\left(\$ / \mathrm{m}^{2}\right)$, housing space per household ( $\mathrm{m}^{2} /$ household), and capital investment intensity (million $\$ / \mathrm{km}^{2}$ ) across the city before introducing an additional major road, respectively. (a')-(d') represent those after introducing an additional major road, respectively.

Table 1 Input parameters for the numerical illustration.

Table 2 Performance of urban system without and with congestion toll schemes.

Table 3 Performance of urban system before and after constructing a new radial major road. 


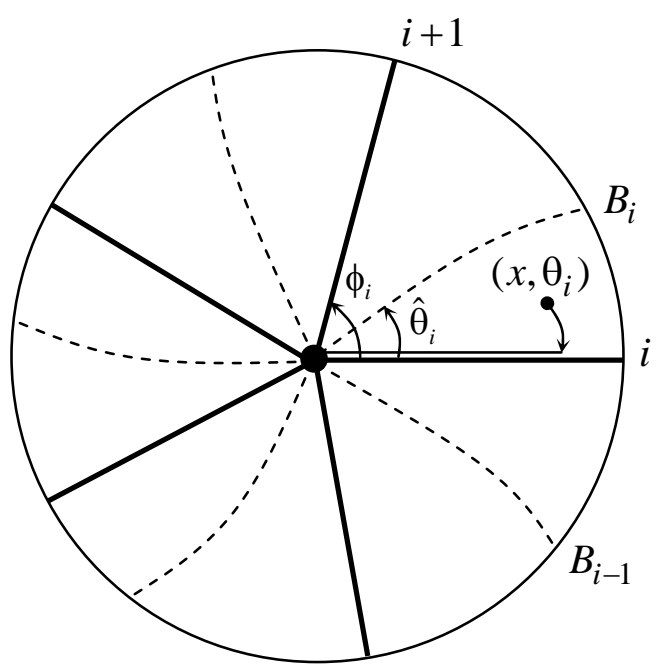

Radial major road

Boundary contour

Fig. 1. A typical circular city with radial major roads. 


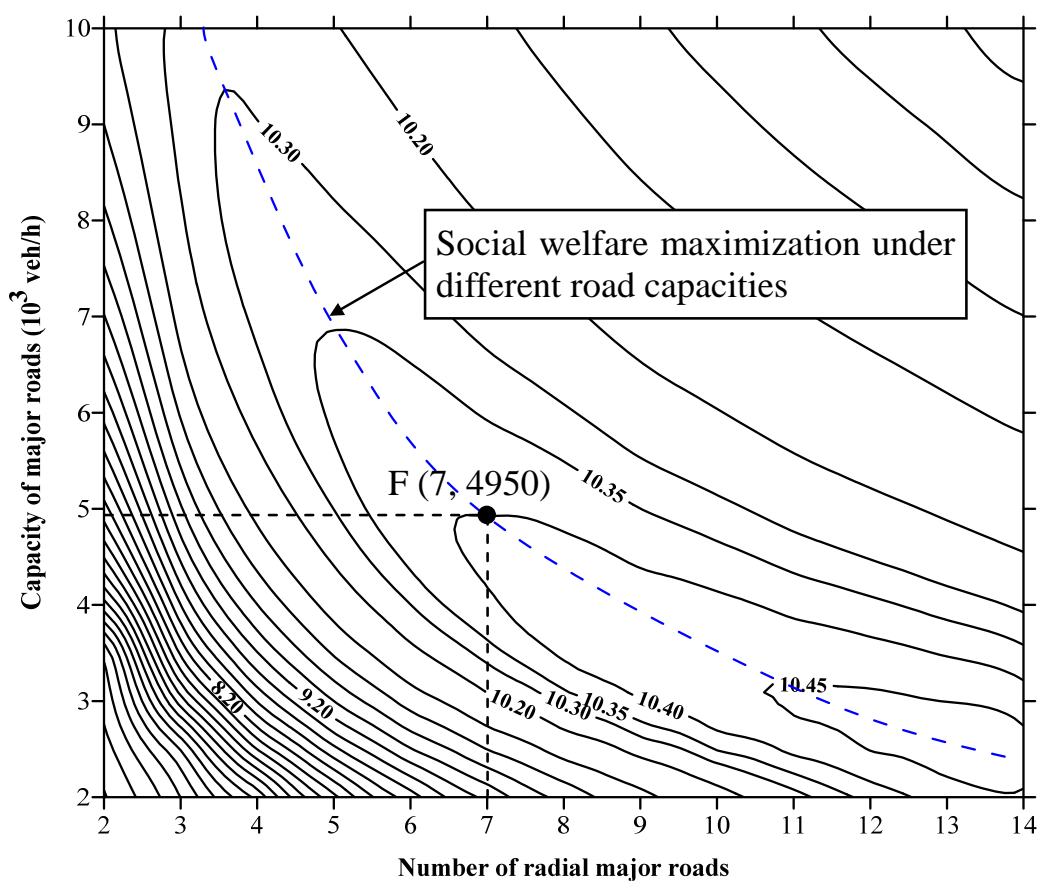

Fig. 2. Change of annual social welfare (billion \$) with the number of radial major roads and the road capacity.

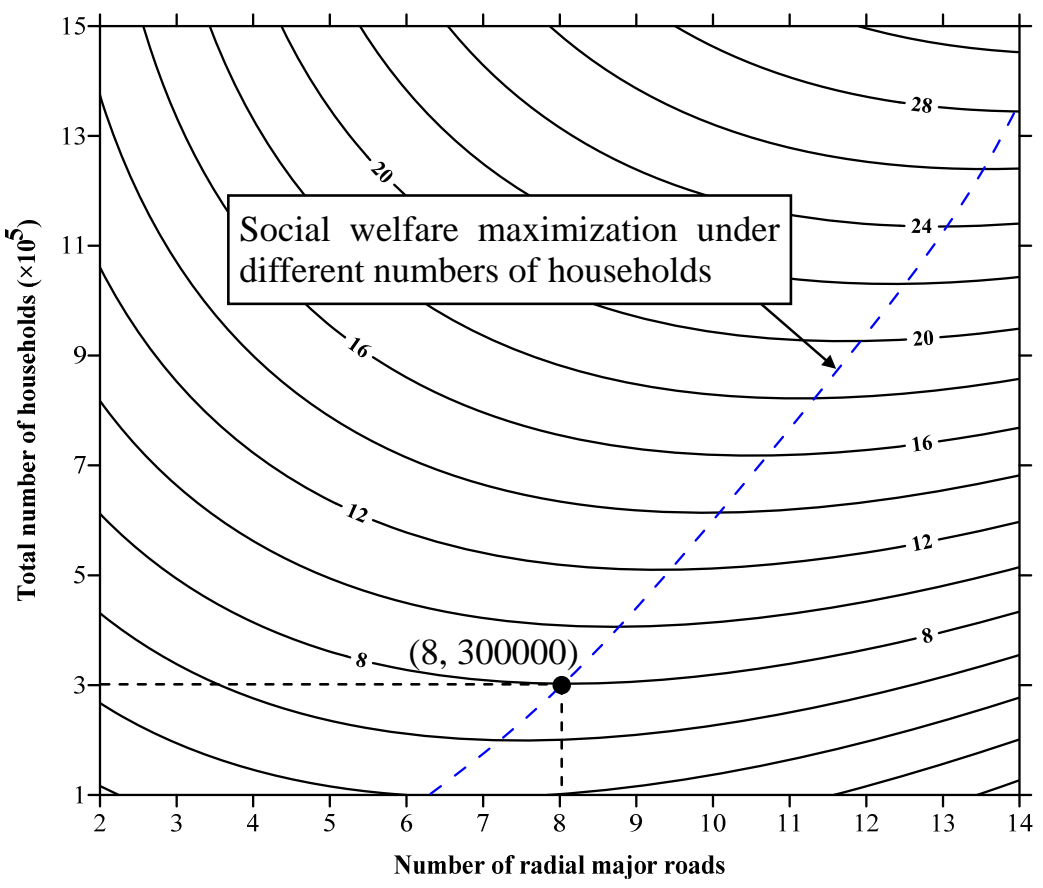

Fig. 3. Change of annual social welfare (billion \$) with the number of radial major roads and the total number of households. 


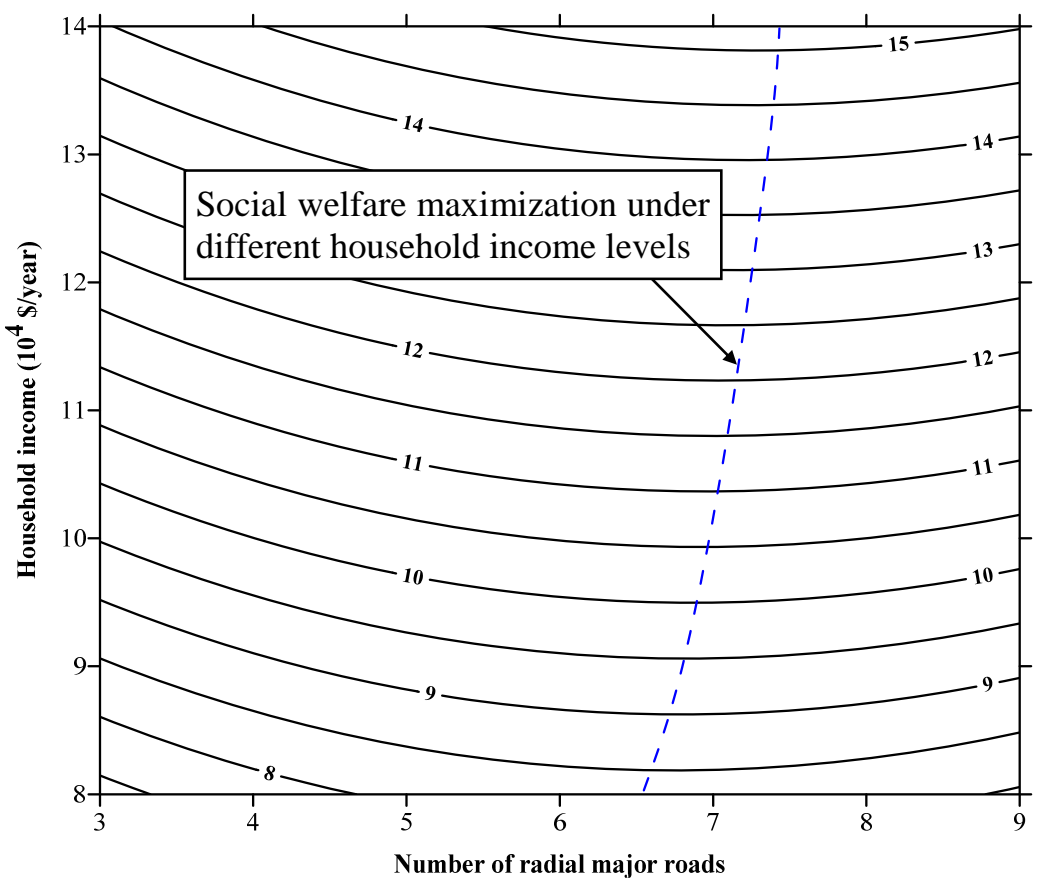

Fig. 4. Change of annual social welfare (billion \$) with the number of radial major roads and the household income level.

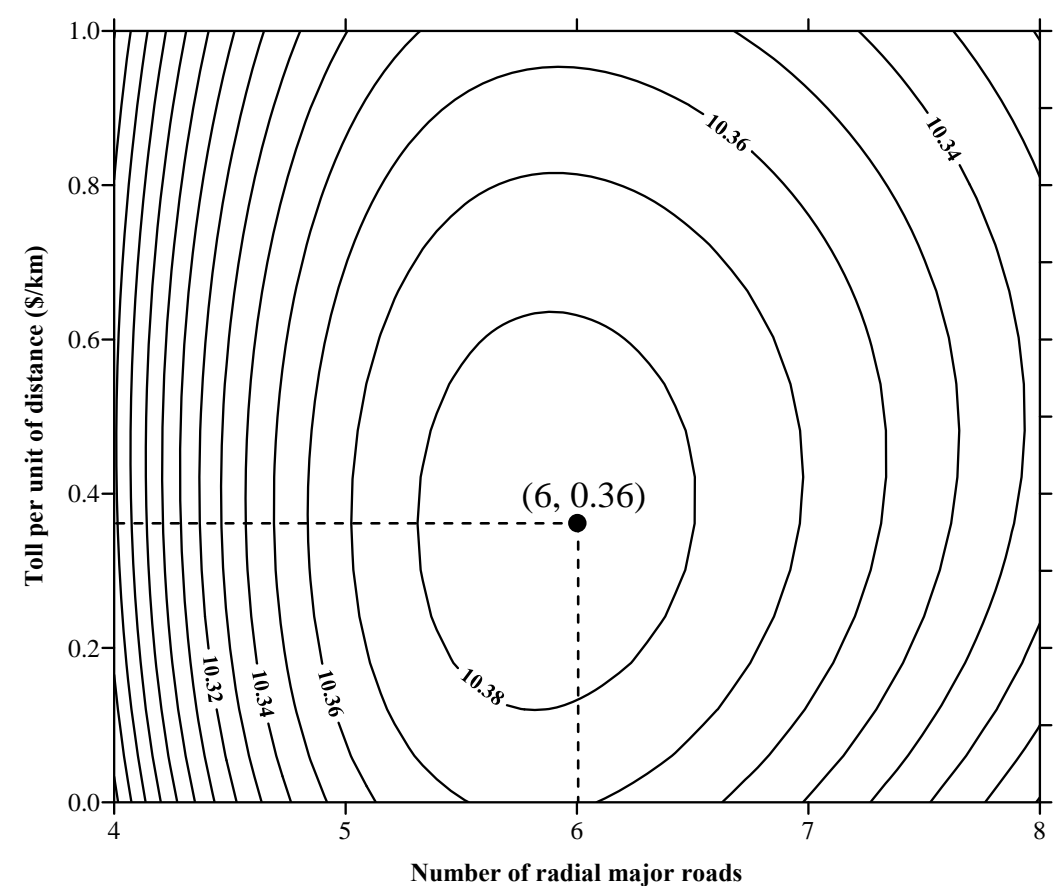

Fig. 5. Change of annual social welfare (billion \$) with the number of radial major roads and the toll per unit of distance. 


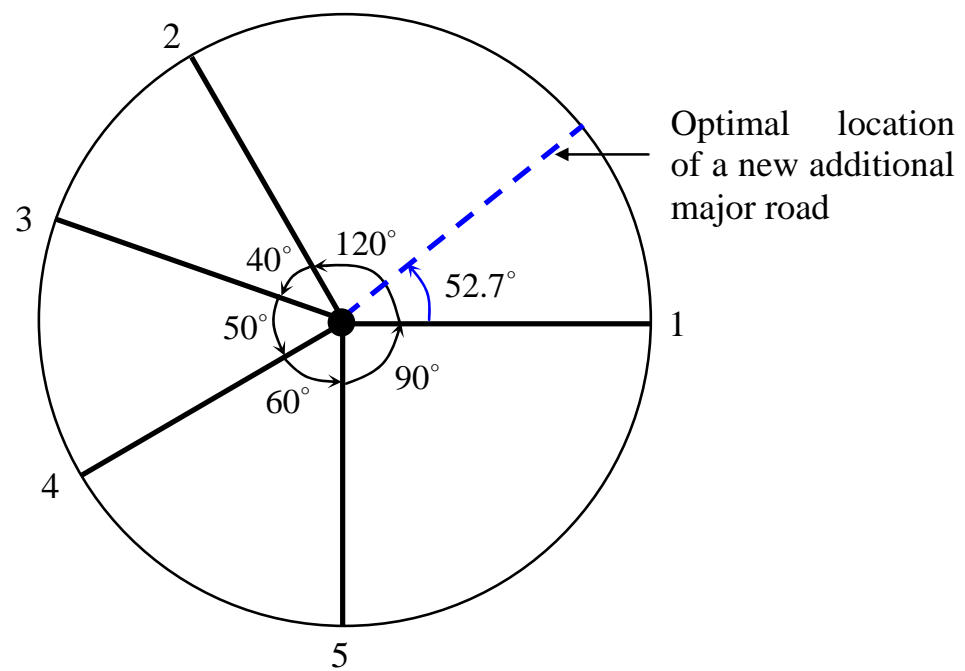

Fig. 6. A city with five radial major roads.

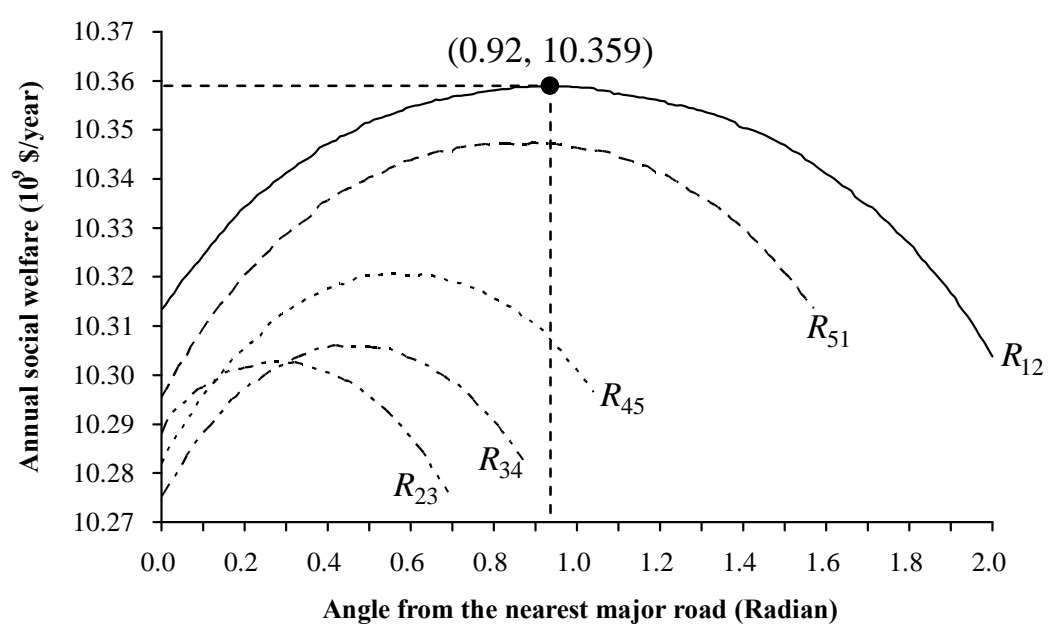

Fig. 7. Change of annual social welfare with the location of a new additional major road. 


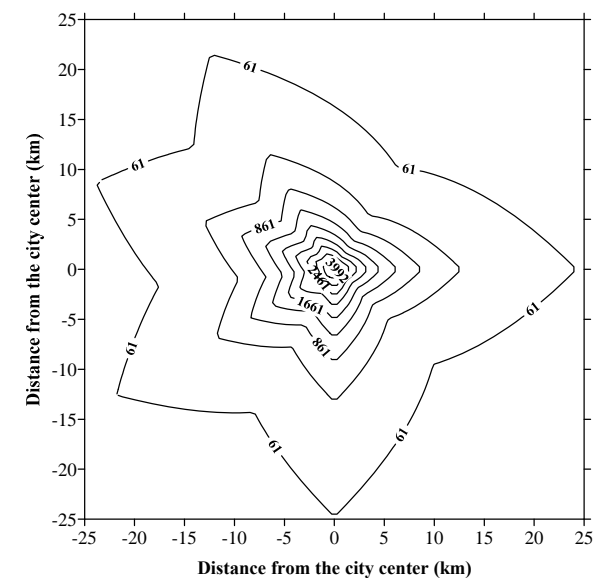

(a)

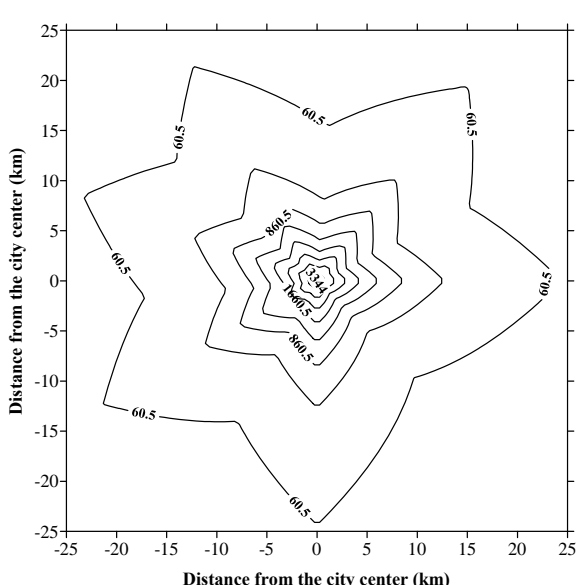

(a')

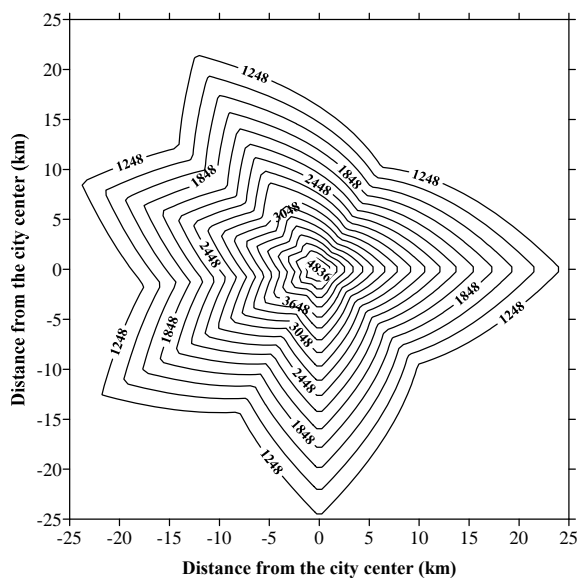

(b)

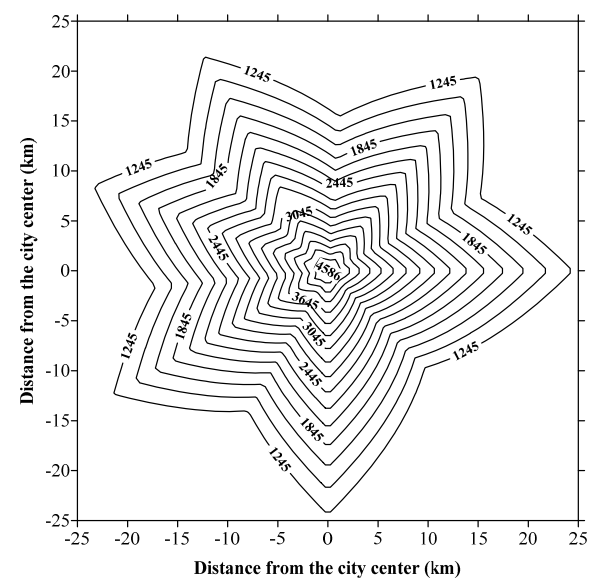

(b')

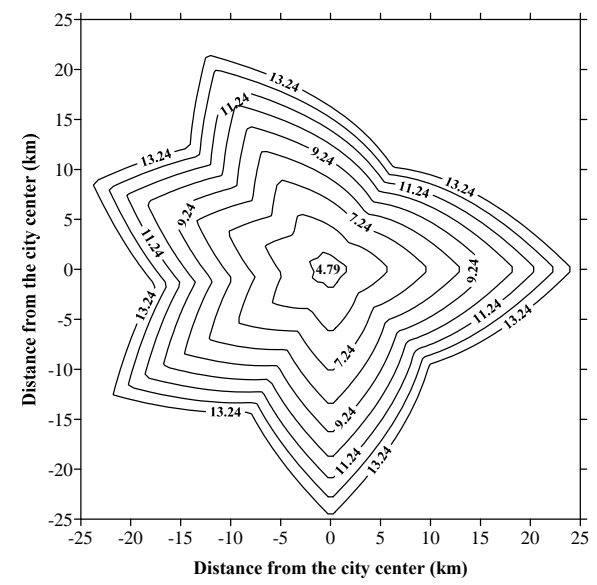

(c)

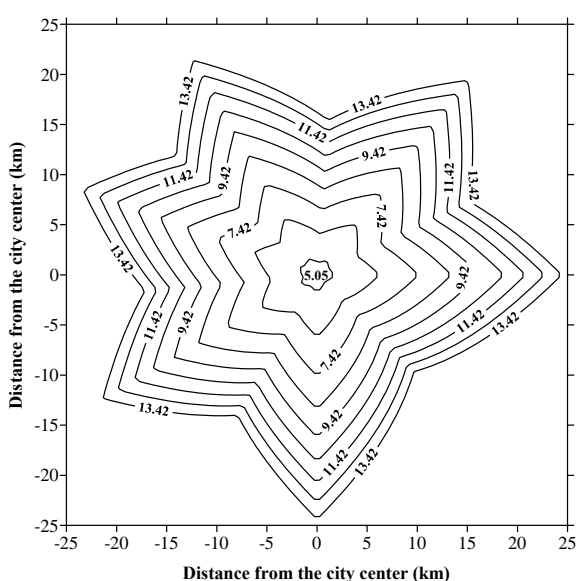

(c')

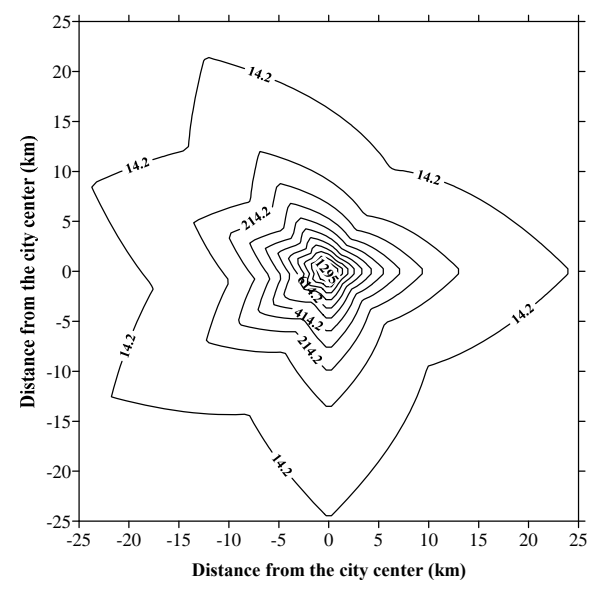

(d)

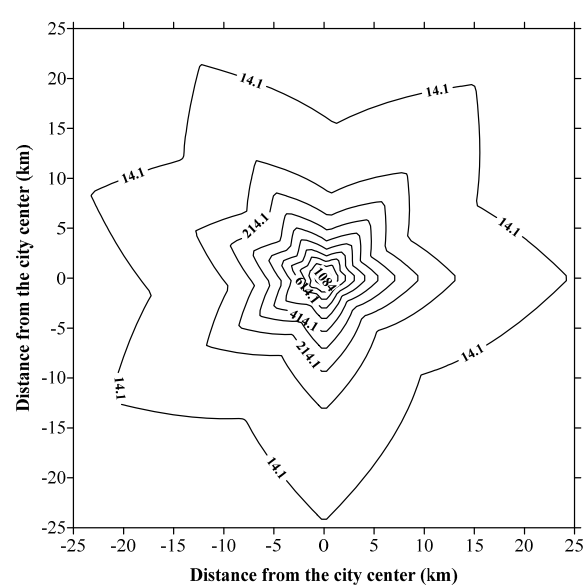

$\left(d^{\prime}\right)$

Fig. 8. (a)-(d) represent household residential density (households $/ \mathrm{km}^{2}$ ), housing price $\left(\$ / \mathrm{m}^{2}\right)$, housing space per household ( $\mathrm{m}^{2} /$ household), and capital investment intensity (million $\$ / \mathrm{km}^{2}$ ) across the city before introducing an additional major road, respectively. (a')-(d') represent those after introducing an additional major road, respectively. 
Table 1 Input parameters for the numerical illustration.

\begin{tabular}{|c|c|}
\hline Parameter & Baseline value \\
\hline$N$ (total number of households in the city) & 500,000 \\
\hline$Y$ (annual household income, \$/year) & 100,000 \\
\hline$K_{i}$ (capacity of major road $i$, veh/h) & 6000 \\
\hline$r_{a}$ (agricultural rent at the city boundary, $\$ / \mathrm{km}^{2}$ ) & 300,000 \\
\hline$\alpha, \beta$ (parameters in household's utility function) & 0.75 and 0.25 \\
\hline$b, \mu$ (parameters in housing production function) & 0.7 and $0.8 \times 10^{-8}$ \\
\hline$k$ (interest rate) & $5 \%$ \\
\hline$c_{i 0}$ (fixed component of monetary travel cost, \$) & 10 \\
\hline$c_{i 1}, c_{i 2}$ (variable component of monetary travel cost, \$/veh-km) & 1.0, and 1.0 \\
\hline$V_{0}$ (average vehicle travel speed, $\mathrm{km} / \mathrm{h}$ ) & 50 \\
\hline$t_{i 0}$ (free-flow travel time per unit of distance, $\mathrm{h} / \mathrm{km}$ ) & 0.02 \\
\hline$\tau$ (value of travel time, $\$ / h$ ) & 20 \\
\hline$\rho$ (average annual number of trips to the city center per household) & 365 \\
\hline$\eta$ (average daily number of trips to the city center per household) & 1.0 \\
\hline$\delta$ (a positive parameter in road construction cost function) & 500 \\
\hline $\begin{array}{l}\zeta \text { (a parameter that converts the utility level of urban households } \\
\text { into the equivalent monetary units) }\end{array}$ & 80 \\
\hline$\xi$ (peak-hour factor) & $10 \%$ \\
\hline
\end{tabular}


Table 2 Performance of urban system without and with congestion toll schemes.

\begin{tabular}{lcc}
\hline \multicolumn{1}{c}{ Performance index } & $\begin{array}{c}\text { No congestion } \\
\text { toll }\end{array}$ & $\begin{array}{c}\text { With congestion } \\
\text { toll }\end{array}$ \\
\hline City size $\left(\mathrm{km}^{2}\right)$ & 1261.1 & 1027.0 \\
Average residential density (households $\left./ \mathrm{km}^{2}\right)$ & 396.5 & 486.9 \\
Average housing space per family $\left(\mathrm{m}^{2} /\right.$ household) & 7.8 & 7.2 \\
Average housing price $\left(\$ / \mathrm{m}^{2}\right)$ & 2061.4 & 2153.7 \\
Average land value $\left(\right.$ million $\left.\$ / \mathrm{km}^{2}\right)$ & 2.4 & 3.0 \\
Average capital investment intensity (million $\left.\$ / \mathrm{km}^{2}\right)$ & 113.1 & 138.5 \\
\hline Household utility level & 203.4 & 198.8 \\
Aggregate land rent (million \$) & 2676.9 & 2739.7 \\
Road construction cost (million $\$$ ) & 441.0 & 385.2 \\
Annual social welfare (million \$) & 10370.2 & 10389.0 \\
\hline
\end{tabular}

Table 3 Performance of urban system before and after constructing a new radial major road.

\begin{tabular}{|c|c|c|}
\hline Performance index & Before & After \\
\hline City size $\left(\mathrm{km}^{2}\right)$ & 1155.1 & 1242.9 \\
\hline Average residential density (households/km²) & 432.9 & 402.3 \\
\hline Average housing space per family (m²/household) & 7.5 & 7.7 \\
\hline Average housing price $\left(\$ / \mathrm{m}^{2}\right)$ & 2094.8 & 2067.7 \\
\hline Average land value (million $\$ / \mathrm{km}^{2}$ ) & 2.6 & 2.5 \\
\hline Average capital investment intensity (million $\$ / \mathrm{km}^{2}$ ) & 122.7 & 114.7 \\
\hline Household utility level & 200.3 & 203.0 \\
\hline Aggregate land rent (million \$) & 2689.7 & 2681.4 \\
\hline Road construction cost (million \$) & 372.9 & 442.8 \\
\hline Annual social welfare (million \$) & 10329.8 & 10358.9 \\
\hline
\end{tabular}

